Int. J. Electrochem. Sci., 13 (2018) 3948 - 3957

\title{
On-Surface Formation of Polyarginine/Reduced Graphene Oxide Film and Its Application in Measuring Puerarin in Healthcare Products
}

\author{
Yufei Li ${ }^{1,2}$, Xiaotong Feng ${ }^{1}$, Lei Zhao ${ }^{1}$, Qiaosheng $\mathrm{Pu}^{1 *}$ \\ ${ }^{1}$ Department of Chemistry, Lanzhou University, Lanzhou, Gansu 730000, China \\ ${ }^{2}$ Gansu Food Inspection and Research Institute, Lanzhou, Gansu 730000, China \\ *E-mail: puqs@1zu.edu.cn
}

doi: $10.20964 / 2018.04 .63$

Received: 20 November 2017 / Accepted: 14 February 2018 / Published: 6 March 2018

\begin{abstract}
Graphene was an ideal material for various applications including electrochemical sensing. To improve the selectivity of graphene-based sensors, preparation of composites of graphene is an effective way. In this work, films of polyarginine/reduced graphene oxide were in-situ formed on the surface of the electrode and used as an electrochemical sensor of puerarin. The films were systematically characterized and the established sensor gave a linear response range from $2.3 \times 10^{-7}$ to $5.5 \times 10^{-6}$ $\mathrm{mol} \cdot \mathrm{L}^{-1}$ and a limit of detection of $4.0 \times 10^{-8} \mathrm{~mol} \cdot \mathrm{L}^{-1}$. The sensor was successfully applied for measuring puerarin in dietary supplements with a relative standard deviation of $2.4 \%$ and a standard recovery of $96.5 \%$.
\end{abstract}

Keywords: graphene oxide, arginine, on-surface polymerization, modified electrode, puerarin

\section{$\underline{\text { FULL TEXT }}$}

(C) 2018 The Authors. Published by ESG (www.electrochemsci.org). This article is an open access article distributed under the terms and conditions of the Creative Commons Attribution license (http://creativecommons.org/licenses/by/4.0/). 